\title{
Redetermination of Hypocenters of Foreshocks, Main Shock, and Aftershocks of the Kita-Izu Earthquake and the Ito Earthquake Swarm of 1930
}

\author{
Akio Yoshida ${ }^{1, *}$ and Nobuo Hamada ${ }^{2}$ \\ ${ }^{1}$ Meteorological Research Institute, Tsukuba 305, Japan \\ ${ }^{2}$ Japan Meteorological Agency, Chiyoda-ku, Tokyo 100, Japan
}

\begin{abstract}
Hypocenters of foreshocks, main shock, and aftershocks of the 1930 Kita-Izu earthquake and the Ito earthquake swarm of 1930 are redetermined. It is clarified that foreshocks of the Kita-Izu earthquake occurred concentrated near the epicenter of the main shock, and almost all aftershocks occurred in the region to the west of the Tanna fault. Some of the aftershocks are located in the northeast coast of Suruga Bay. A spatial complementarity is seen between the aftershock area of the Kita-Izu earthquake and the recent active region since 1974, that is, recent seismicity is active to the east of the Tanna fault. Foreshock activity of the Kita-Izu earthquake began about 3 weeks before the main shock. It reached to the culmination in the evening of 25 th November when the largest foreshock (M5.1) occurred at $16 \mathrm{~h} 5 \mathrm{~m}$. Then the foreshock activity gradually decreased and it was rather quiet a few hours before the main shock occurring at $4 \mathrm{~h} 2 \mathrm{~m}$ on the $26 \mathrm{th}$. The aftershock activity did not decrease according to the Omori's formula, but showed intermittent increase. The Ito earthquake swarm in the spring of 1930 occurred in almost the same region as that of recent swarm activity off the east coast of the Izu Peninsula. There were two peaks in the swarm activity of 1930, i.e., in March and in May. It seems that swarm activity in March occurred somewhat nearer to the east coast of the Izu Peninsula than that in May, although the difference is not so clear. If the number of earthquakes with $M 4$ or larger in the 1930 swarm activity, 70 , is compared to the total number of earthquakes with $M 4$ or larger in the recent activities from 1978 through 1989,90 , it can be said that the swarm in the spring of 1930 was remarkably active.
\end{abstract}

\section{Introduction}

After the occurrence of the 1930 Kita-Izu earthquake (M7.3), seismicity around the Izu Peninsula had been low until the resumption of activity in the mid-1970 s, when the 1974 Izu-hanto-oki earthquake (M6.9) occurred. Since then, very high level seismic activity has been continuing around the Izu Peninsula, and the region is now the most active in the Japanese Islands and their coast areas. Hence it is interesting and considered important as well for the study of seismotectonics around the Izu Peninsula to investigate

Received October 31, 1990; Accepted February 6, 1991

* To whom correspondence should be addressed. 
the activity associated with the $1930 \mathrm{Kita}-\mathrm{Izu}$ earthquake in detail and to elucidate differences between the $1930 \mathrm{~s}$ and the recent activities.

In the meanwhile it has been pointed out that the tendency of northward migration of seismicity is observed in the Izu region (Rikitake, 1980 ; Mogi, 1981 ; Yoshida, 1982). The migration front is now near the latitude of $35^{\circ}$, and a quiescence has been recognized in the zone to the north of this line, where a large earthquake is expected to occur in the near future (e.g., Mogi, 1981). Further, Ishibashi (1985) has predicted an occurrence of "Odawara earthquake" in the $1990 \mathrm{~s}$ by the periodicity of large earthquake occurrence in the western Kanagawa Prefecture, which is located in the quiescence zone.

The $1930 \mathrm{Kita}-\mathrm{Izu}$ earthquake occurred just in the quiescent region abovementioned. After the occurrence seismic activity diffused to the north-to the eastern Yamanashi and to the southern Saitama, and to the west-to the coast area of Suruga Bay ( Mogi, 1980; Yoshida, 1987). It may be important to clarify the spreading of seismic activity after the Kita-Izu earthquake from the viewpoint of estimating the future development of recent activities. Further, the Kita-Izu earthquake is known to have been accompanied by remarkable foreshock activity. Time sequence of the foreshock activity and the epicenters relative to that of the main shock are interesting in relation with the problem of the prediction of intraplate earthquake of $M 7$ class. Moreover, violent swarm earthquakes were observed in the spring of 1930 in the region off the east coast of the Izu Peninsula near Ito City, where swarm activities have been continuing intermittently since 1978 . It is interesting to see the difference of space-time pattern between the swarm activity in 1930 and those in recent years. Concerning these problems it has been difficult to investigate in detail so far, for hypocentral data of the published JMA Catalogue (e.g., JMA, 1982) were not accurate enough. Recently, Hamada (1987) showed that hypocenters could be determined fairly well by the method using $\mathrm{P}$ and $\mathrm{S}$ arrival times even for earthquakes in the $1930 \mathrm{~s}$ through $1950 \mathrm{~s}$, provided that accuracy and time shift of reported reading times of $\mathrm{P}$ and $\mathrm{S}$ phases are taken into consideration properly. In this paper, hypocenters of foreshocks, main shock and aftershocks of the Kita-Izu earthquake as well as the earthquake swarm of 1930 were redetermined and characteristics of their space-time distribution are discussed referring to the above-mentioned problems.

\section{Data and Method of Hypocenter Determination}

Data are taken from the original observation registers of earthquakes of the Japan Meteorological Agency. At the time of 1930 there were two observatories in the northern Izu Peninsula. They are the Mishima weather station and the Numazu weather station. The Mishima weather station was established after the Ito swarm activity occurring in the spring of 1930, and consequently, there were no data about the swarm. Instead the Ito temporary station had been set up during the swarm activity. Accuracy of time at the Ito station, however, was not so good that we could not use much the data effectively in the calculation of hypocenter determination. As shown in Fig. 1 there were observatories such as Yokohama, Yokosuka, Tokyo, Tomisaki, Kumagaya, Hamamatsu, Kofu, and Iida in the circumference area of the Izu Peninsula, and each observatory was equipped with a Wiechert seismograph. Accuracy of hypocenters 


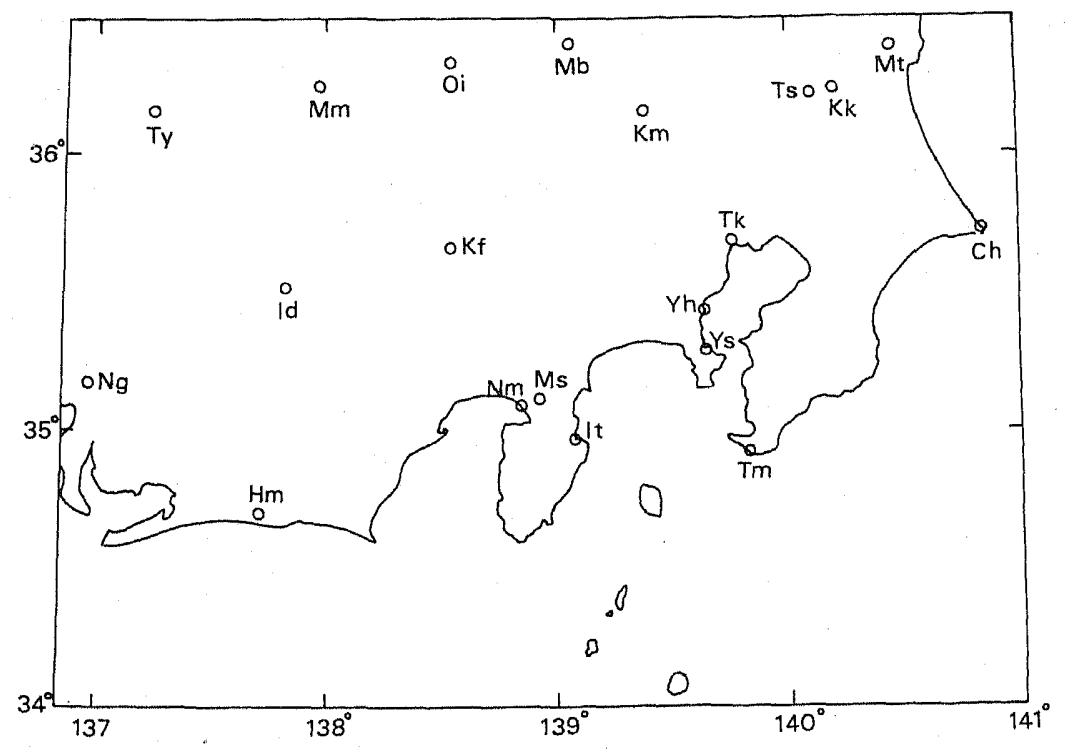

Fig. 1. Observation stations that were at work in 1930. Ch, Choshi; Hm, Hamamatsu; Id, Iida; It, Ito; Kf, Kofu; Kk, Kakioka; Km, Kumagaya; Mb, Maebashi; Mm, Matsumoto; Ms, Mishima; Mt, Mito; Ng, Nagoya; Nm, Numazu; Oi, Oiwake; Tk, Tokyo; Tm, Tomisaki; Ts, Tsukuba; Ty, Takayama; Yh, Yokohama; Ys, Yokosuka.

depends largely on the accuracy of the reading times of $\mathrm{P}$ and $\mathrm{S}$ phases at these observatories. An extended investigation on the general state concerning the accuracy of reading times of seismograms in $1930 \mathrm{~s}$ through $1950 \mathrm{~s}$ is reported by Hamada (1987). For the Kita-Izu earthquake and the Ito earthquake swarm of 1930 , reading of $P$ and $\mathrm{S}$ arrival times at Mishima, Yokohama, Tomisaki, and Kumagaya were generally good-time lag is small and errors of the reading times are considered about or within 1s. At Yokosuka, Tokyo, and Hamamatsu and others, shift of time was often pretty large-sometimes more than $10 \mathrm{~s}$, however, S-P times could be used effectually for these stations. Just after the occurrence of the Kita-Izu earthquake errors of reading time were so large for almost all the stations because of run-down of clocks that we could not determine hypocenters including some of rather large earthquakes.

We used Hamada's method (Hamada et al., 1984; Hamada, 1987) to calculate hypocenters of earthquakes. This is to make the sum of square of travel time differences, $R$, to the least value

$$
R=\sum_{i}\left\{W_{\mathrm{p}}\left(O_{i}-C_{i}\right)_{\mathrm{p}}\right\}^{2}+\sum\left\{W_{\mathrm{s}}\left(O_{i}-C_{i}\right)_{\mathrm{s}}\right\}^{2}+\sum\left\{W_{\mathrm{sp}}\left(O_{i}-C_{i}\right)_{\mathrm{sp}}\right\}^{2}
$$

The velocity structure is the same as that used now by JMA (Hamada, 1984). In Eq. (1), the first term is for P phase, the second is for S phase and the third is for S-P time. $W_{\mathrm{p}}, W_{\mathrm{s}}$, and $W_{\mathrm{sp}}$ express weights for $\mathrm{P}$ reading time, $\mathrm{S}$ reading time, and $\mathrm{S}-\mathrm{P}$ time, 
respectively. Because accuracy of reading time for $\mathrm{P}$ phase is better than that for $\mathrm{S}$ phase generally we set $W_{\mathrm{p}}>W_{\mathrm{s}}$ and assigned the smallest value to $W_{\mathrm{sp}}$. We chose values $1.0,0.44721,0.22361$ for $W_{\mathrm{p}}, W_{\mathrm{s}}$, and $W_{\mathrm{sp}}$, respectively. The third term is not incorporated in the hypocenter determination program used at present in the Japan Meteorological Agency, but it was contained in order to use S-P time effectively. Generally in the final calculation we did not use data of reading time whose O-C time exceeds $2 \mathrm{~s}$ for $\mathrm{P}$ phase, $3 \mathrm{~s}$ for $\mathrm{S}$ phase and $5 \mathrm{~s}$ for $\mathrm{S}-\mathrm{P}$ time. We used arrival times of $\mathrm{P}$ phase and $\mathrm{S}$ phase as much as possible so long as they were reported; however, $\mathrm{S}-\mathrm{P}$ time was taken in such cases that both the difference of $\mathrm{O}-\mathrm{C}$ for $\mathrm{P}$ time and $\mathrm{S}$ time exceeded $3 \mathrm{~s}$. Further, for the nearest stations Mishima and Numazu, we adopted S-P time even when $\mathrm{O}-\mathrm{C}$ for $\mathrm{P}$ time was less than $3 \mathrm{~s}$ but exceeded about $2 \mathrm{~s}$. The number of earthquakes thus determined is 40 for foreshocks and 43 for aftershocks during the period until the end of December 1930. These numbers of earthquakes are larger than those contained in the JMA Earthquake Catalogue so far published (JMA, 1982).

\section{Foreshocks}

Figure 2 shows the epicentral distribution of the main shock and foreshocks of the Kita-Izu earthquake. The redetermined hypocenter of the main shock is $\lambda 138.58 .8^{\prime}$, $\phi 35.02 .4^{\prime}$, depth $1.4 \mathrm{~km}$, and the origin time is $26 \mathrm{~d} 04 \mathrm{~h} 02 \mathrm{~m} 47.0 \mathrm{~s}$. The epicenter nearly coincides with the surface trace of the Tanna fault. Foreshocks plotted in Fig. 2 are those after 16th November, however, it is known from the records at the Mishima weather station that the foreshock activity itself was started earlier-small earthquakes began to occur probably from 7 th November. Earthquakes with hypocentral depths shallower than or equal to $30 \mathrm{~km}$ are plotted in Fig. 2. Number of foreshocks whose hypocenters are determined is 40 , while 34 foreshocks are given in the Earthquake Catalogue of JMA (JMA, 1982). For most of them, i.e., 35 among 40, calculation errors of latitude and longitude are within $\pm 3^{\prime}$ ( actually more than half are less than $\pm 2^{\prime}$ ), and depths of more than three quarters of these earthquakes are less than $10 \mathrm{~km}$-only 3 earthquakes have depths exceeding $20 \mathrm{~km}$. Consequently it is considered that the accuracy of earthquake epicenters in Fig. 2 is about several minutes, and most of foreshocks are very shallow.

A notable feature of the epicentral distribution of foreshocks is that most of them are located near the epicenter of the main shock, which feature is commonly observed for many foreshock activities of intraplate large earthquakes in the Japanese Islands (Hamada, 1987; Yoshida, 1990). It is interesting to note that the epicenter of the main shock corresponds to the jointing part of the segments of the Tanna fault investigated by Matsuda (1975).

Figure 3(A), (B) shows number of earthquakes per each day in November and December 1930 observed at the Mishima weather station (Central Weather Observatory, 1931) and at the Numazu weather station (Numazu Weather Station, 1931), respectively. It is seen that the foreshock activity became clearly recognizable since 11 th and there were conspicuous concentrated activities on the 15th, 16th, 20-21st, 23rd, and 25th intermittently. The activity on 25 th November was particularly severe and it reached the culmination when the largest foreshock with a magnitude of 5.1 occurred at $16 \mathrm{~h}$ 


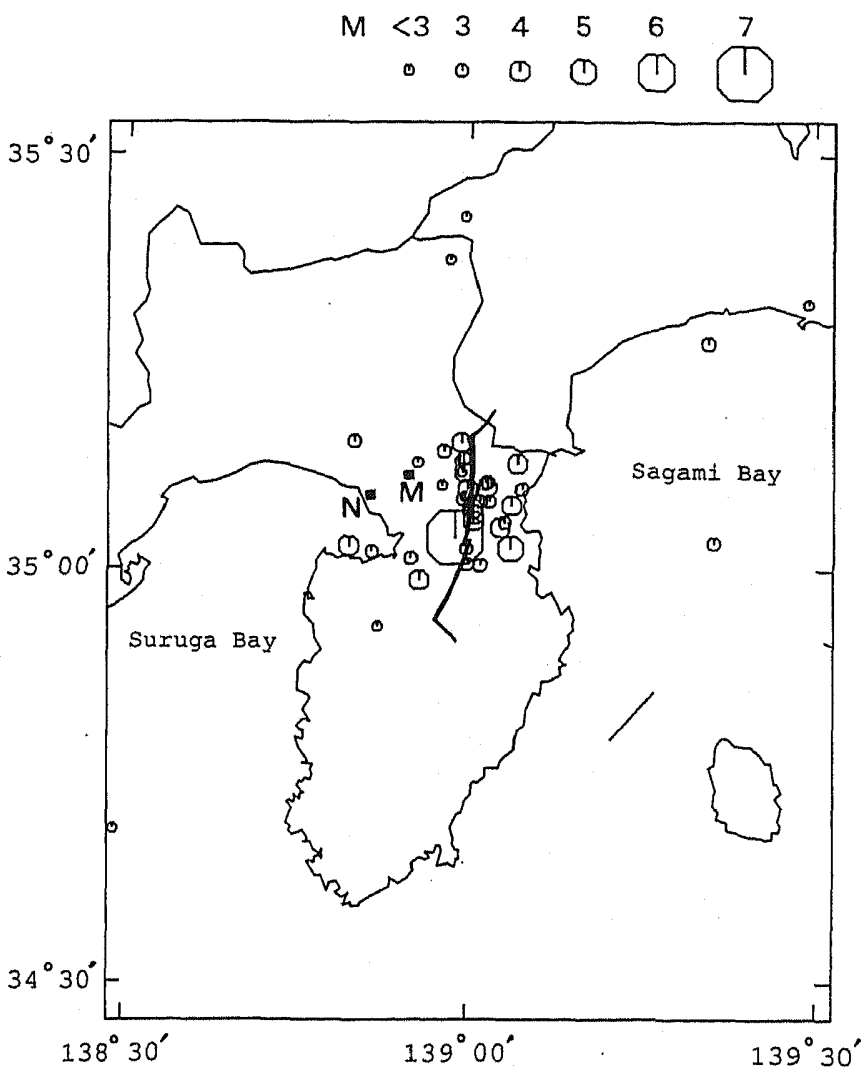

Fig. 2. Epicentral distribution of the main shock and foreshocks of the Kita-Izu earthquake (period: 16th-26th November 1930). The largest circle shows the epicenter of the main shock and the solid line which passes through near the epicenter of the main shock represents surface trace of the Tanna fault (Matsuda, 1975 ). M, Mishima weather station; N, Numazu weather station.

$05 \mathrm{~m}$ about $12 \mathrm{~h}$ before the main shock. Then, the foreshock activity gradually decreased and it was rather quiet during a few hours just before the main shock. It is clearly seen from Fig. 3 that the foreshock activity of the Kita-Izu earthquake was abnormally high. The number of observed foreshocks was larger than that of aftershocks at both Mishima and Numazu stations.

\section{Aftershocks}

Figure 4 shows the epicentral distribution of aftershocks during the period 26th November through 31st December 1930. Earthquakes with focal depths shallower than $30 \mathrm{~km}$ are plotted. The number of those earthquakes is 43 , while 33 aftershocks are given in the JMA Catalogue (JMA, 1982) for the same period. If Fig. 4 is compared with Fig. 2 for foreshocks, it is clear that aftershocks occurred in wider areas than foreshocks.

Vol. 39, No. 1, 1991 

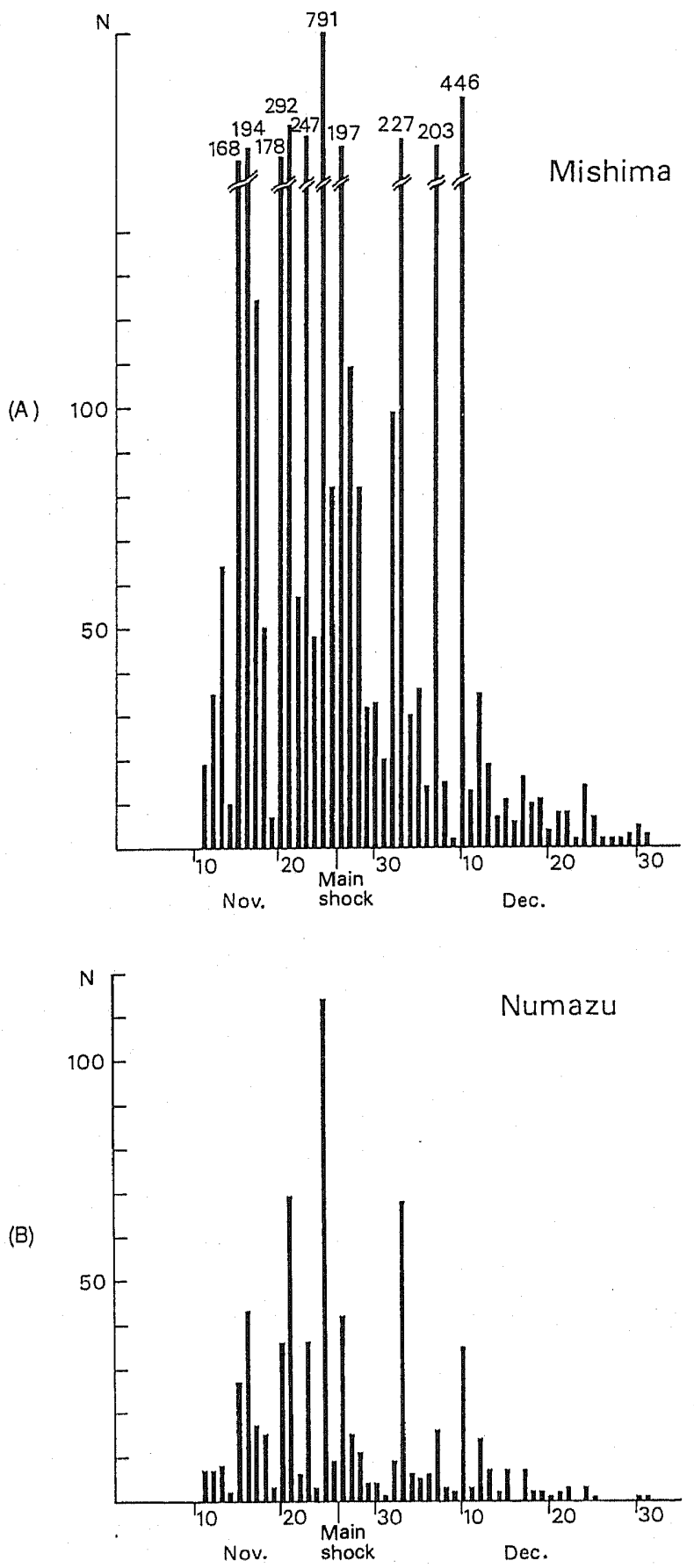

Fig. 3. Number of earthquakes observed per each day in November and December 1930. (A) Mishima weather station; (B) Numazu weather station. 


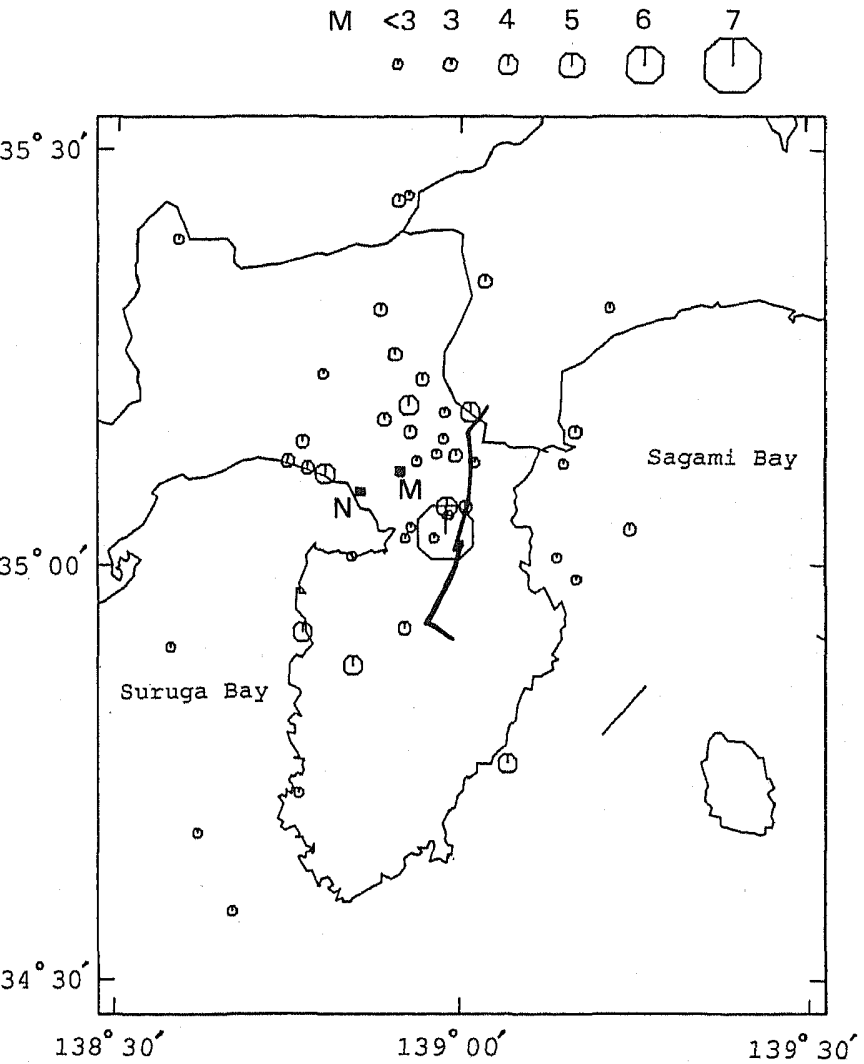

Fig. 4. Epicentral distribution of the main shock and aftershocks of the KitaIzu earthquake during the period 26 November through 31 December 1930. The largest circle shows the epicenter of the main shock, and the solid line passing through it represents the Tanna fault. M, Mishima weather station; $\mathrm{N}$, Numazu weather station.

The fact that aftershocks were distributed in a wider region than foreshocks is also confirmed by Fig. 5(A), (B), which shows frequency distribution of S-P times of foreshocks and aftershocks during the period 26th November through 31st December 1930 at the Mishima weather station (Central Weather Observatory, 1931) and at the Numazu weather station (Numazu Weather Station, 1931), respectively. A remarkable feature is that most of the aftershocks are distributed to the western side of the Tanna fault, that is, a conspicuous asymmetry is observed in the spatial distribution of aftershocks between the east and the west sides of the fault plane. Earthquakes around the northern coast of Suruga Bay occurred more than 2 weeks after the main shock. Their hypocenters are well determined and it is certain that aftershock activity extended to that region. The fact that there are such earthquakes whose S-P time at the Numazu weather station is shorter than that at the Mishima weather station also indicates that aftershock activity diffused to the west.

Vol. 39, No. 1, 1991 

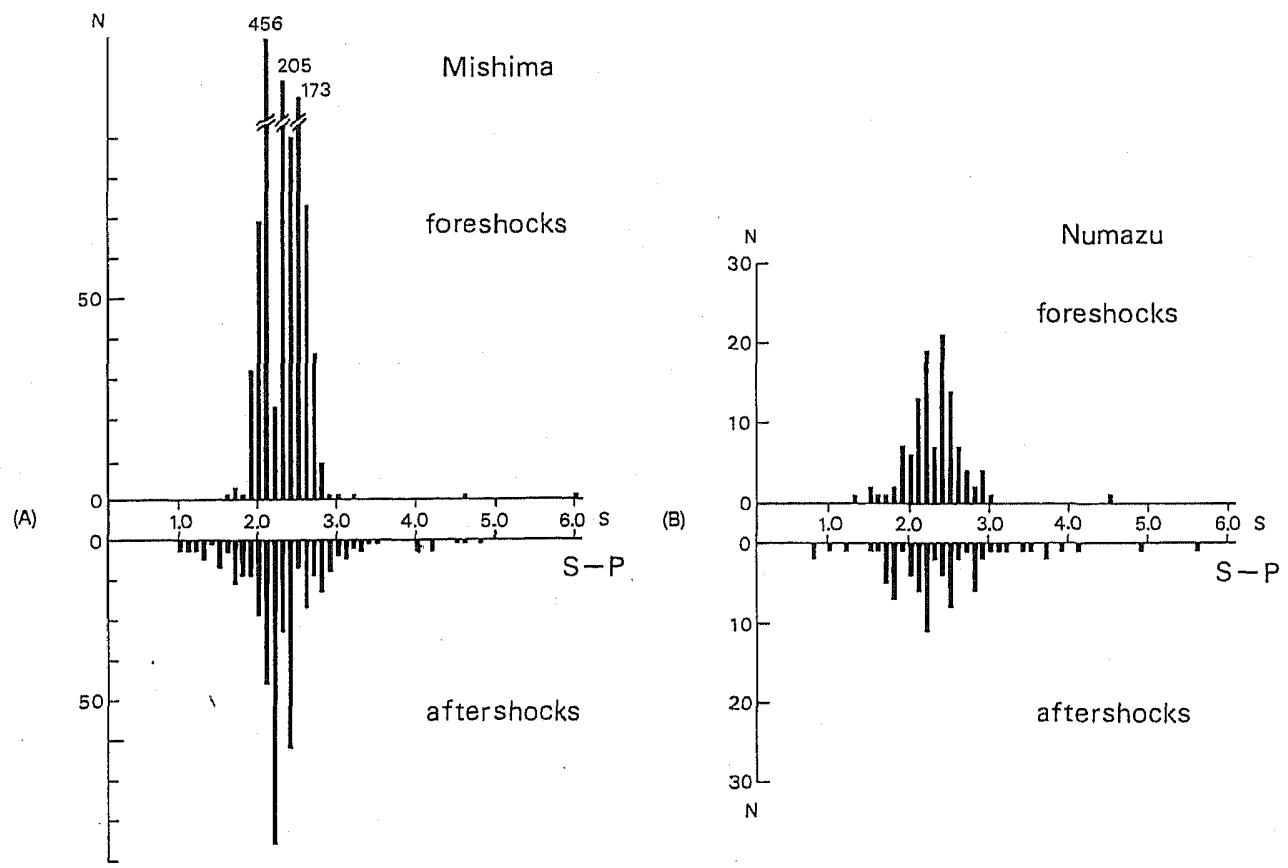

Fig. 5. Distribution of S-P times of foreshocks and aftershocks during November and December of 1930. (A) Mishima weather station. (B) Numazu weather station.

Seismic activity in 1931 around the Izu Peninsula is shown in Fig. 6. Moderate earthquakes with magnitudes of 5.3 and 5.4 occurred successively on 7th March on the northern coast of Suruga Bay, where several aftershocks were observed in December 1930 (see Fig. 4). There was also a notable activity in the eastern Yamanashi Prefecture including a large earthquake with a magnitude of 5.9 in June. Subsequently in September 1931, the Nishi-Saitama earthquake with a magnitude of 6.9 occurred to the north of eastern Yamanashi (outside of the region of Fig. 6). A migration tendency of seismic activity further to the north along this zone has been noted by Mogi (1969) (also Yoshida, 1988). On the other hand seismicity diffused to the west as well, and the Shizuoka earthquake with a magnitude of 6.3 occurred on the west coast of Suruga Bay in 1935.

When the main shock occurred clocks at all weather stations near the epicenter stopped and reported reading times were very confused so that we could not determine hypocenters including rather large earthquakes just after the main shock. However, accuracy of earthquake epicenters plotted in Fig. 4 is considered as same as that for foreshocks in Fig. 2. Calculated errors of latitudes and/or longitudes exceed $3^{\prime}$ for only 6 earthquakes among 43 (more than half are less than $\pm 2^{\prime}$ ), and depths are shallower than $10 \mathrm{~km}$ for about $90 \%$ of earthquakes in Fig. 4. On the other hand, depths of earthquakes occurring in the eastern Yamanashi Prefecture in 1931 are determined to be about $30 \mathrm{~km}$ in average, which is concordant with hypocentral depths of earthquakes 


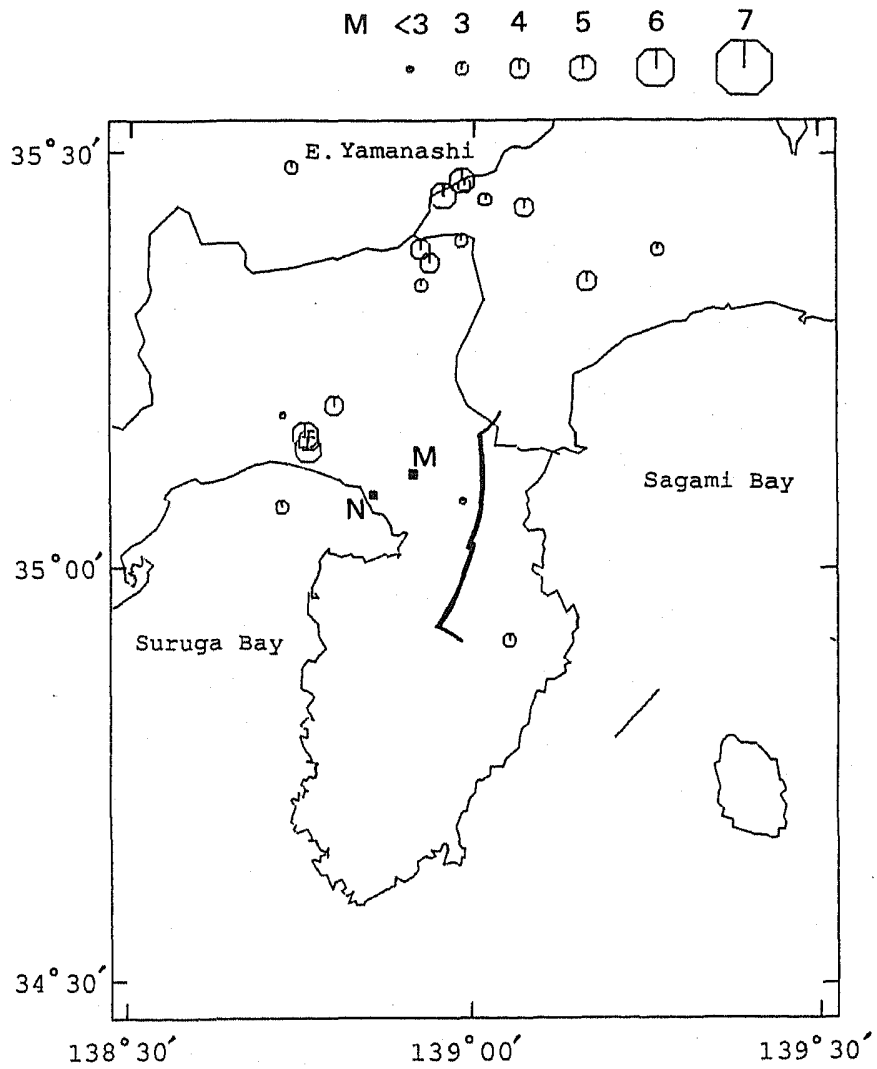

Fig. 6. Seismic activity in 1931 around the Izu Peninsula. The solid line represents the Tanna fault. M, Mishima weather station; N, Numazu weather station.

in the region clarified by precise calculation using data of recent dense observation net.

It is remarkable that no aftershock with a magnitude larger than 5 was observed. This is not usual for such a large main shock with a magnitude of 7.3. Another notable feature of aftershock activity is that it did not decrease according to the Omori's formula, but showed remarkable increase of activity intermittently. Activities on 3rd, 7th, and 10th in December were especially conspicuous (see Fig. 3(A), (B)). Such a pattern of aftershock activity is similar to the activity after the 1980 Izu-hanto-toho-oki earthquake with a magnitude of 6.7 (OIEP, JMA, 1981).

As is seen in Fig. 7 the feature that most aftershocks are distributed to the west of the Tanna fault can not be seen at all from published hypocentral data of JMA (JMA, 1982). However, Hayata (1931) already pointed out in 1931 that epicentral distribution of aftershocks was very different from that of foreshocks. That is, aftershocks were distributed in a wider region to the north and to the west, in the Hakone region, the foot of Mt. Fuji, Ashigara mountain, the west coast of Suruga Bay and the eastern Yamanashi Prefecture. Further, he also noted from the comparison of observed records 


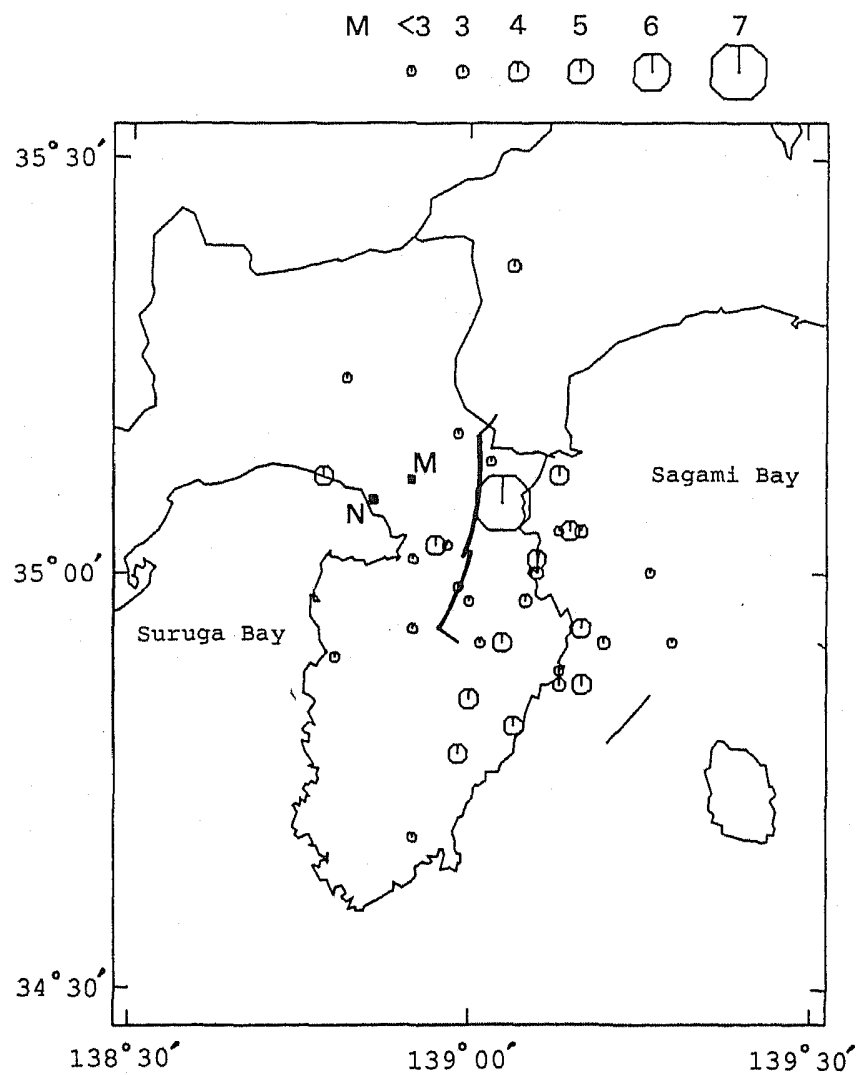

Fig. 7. Epicentral distribution of aftershocks of the Kita-Izu earthquake using hypocentral data of the Seismological Bulletin of the Japan Meteorological Agency, Supplementary Volume No. 6 (JMA, 1982). The largest circle shows the epicenter of the main shock, and the solid line passing near it represents the Tanna fault. M, Mishima weather station; N, Numazu weather station.

that arrival time at the Numazu weather station was earlier than that at the Mishima weather station for some of the aftershocks, indicating that epicenters of aftershocks spreaded to the west and there occurred such earthquakes whose epicentral distance to Numazu was shorter than that to Mishima.

\section{Ito Earthquake Swarm}

There were severe earthquake swarms in the east coast of the Izu Peninsula in March and in May of 1930. In that region, swarm activities have been observed intermittently since November 1978, and it is interesting to compare the swarm activities in 1930 and those in recent years. Figures 8, 9, 10 show redetermined epicentral distributions of earthquakes in March, April, and May of 1930, respectively. Comparing 
these distributions with that of recent activity since 1974 through 1989 shown in Fig. 11 , we see that the active regions in 1930 and in recent years are almost overlapping. A diffusive distribution of the swarm earthquakes of 1930 may be partly due to the less accuracy of hypocenters, and it is considered that the swarm region in 1930 was actually more compact. It seems that the activities in 1930 occurred very near the east coast of the Izu Peninsula, nearer than the central part of the recent swarm activities. Although the difference of spatial distributions between swarm earthquakes in March and those in May is not clearly seen, it is conjectured from comparison of the distributions of S-P times at near stations that the swarm activity in March occurred more close to the coast of the Izu Peninsula than that in May.

The number of relocated earthquakes is 100 and 116 for the activities in March and in May, respectively. Focal depths of these swarm earthquakes are calculated to be shallower than $10 \mathrm{~km}$ for more than $60 \%$ of them (depths of all the earthquakes in Figs. 8, 9, 10 are less than $20 \mathrm{~km}$ ), and no difference can be recognized between the depths of the activities in March and in May. According to Ueki et al. (1990), in which hypocenters of the Ito swarm earthquakes in March of 1930 were relocated using data by the Earthquake Research Institute, Univ. Tokyo, the swarm earthquakes were distributed in the depth range between $5-10 \mathrm{~km}$. Ueki et al. (1990) estimated from the result that the magma activity in 1930, which was first suggested by Kuno (1954), was stopped at the depth of $5 \mathrm{~km}$ below the surface. Anyway, for the Ito swarm activity in 1930 we could not find any record of volcanic tremor which indicates rise of magma near the surface.

Figures 12 and 13 show epicentral distributions of earthquakes with magnitude 4 or larger in the spring of 1930 and that in the period from 1978 through 1989, respectively. The number of earthquakes with magnitude 4 or larger in the swarm of 1930 reached as many as 70 including 6 earthquakes above magnitude 5, while the sum of the earthquakes with magnitude 4 or larger in the recent activities in the east off-Ito since 1978 including aftershocks of the 1980 Izu-hanto-toho-oki earthquake (M6.7) is 90 . If these two numbers are compared, it might be said that the swarm activity in 1930 was remarkably active.

\section{Discussion}

Some tectonic meaning must exist in the feature that most aftershocks of the Kita-Izu earthquake occurred in the region to the west of the Tanna fault. Analyzing change of level and horizontal strain before and after the Kita-Izu earthquake, Tsuboi (1932) found that there were block movements in the region to the west of the Tanna fault, and estimated that the western side to the Tanna fault moved actually at the Kita-Izu earthquake. It is not a rare phenomenon that aftershocks are asymmetrically distributed in the both sides to the fault plane. Yoshida and Mori (1987) reported several such cases wherein most aftershocks occur in either one side to the fault plane for strike-slip-type earthquakes in the Japanese Islands. They pointed out several possibilities about the cause of the phenomenon: either one side actually moved, the strength of block differs between the two sides of the fault, or it reflects tectonic process of strain accumulation. It may be also possible to consider that the feature of spatial distribution

Vol. 39, No. 1, 1991 
A. Yoshida and N. Hamada
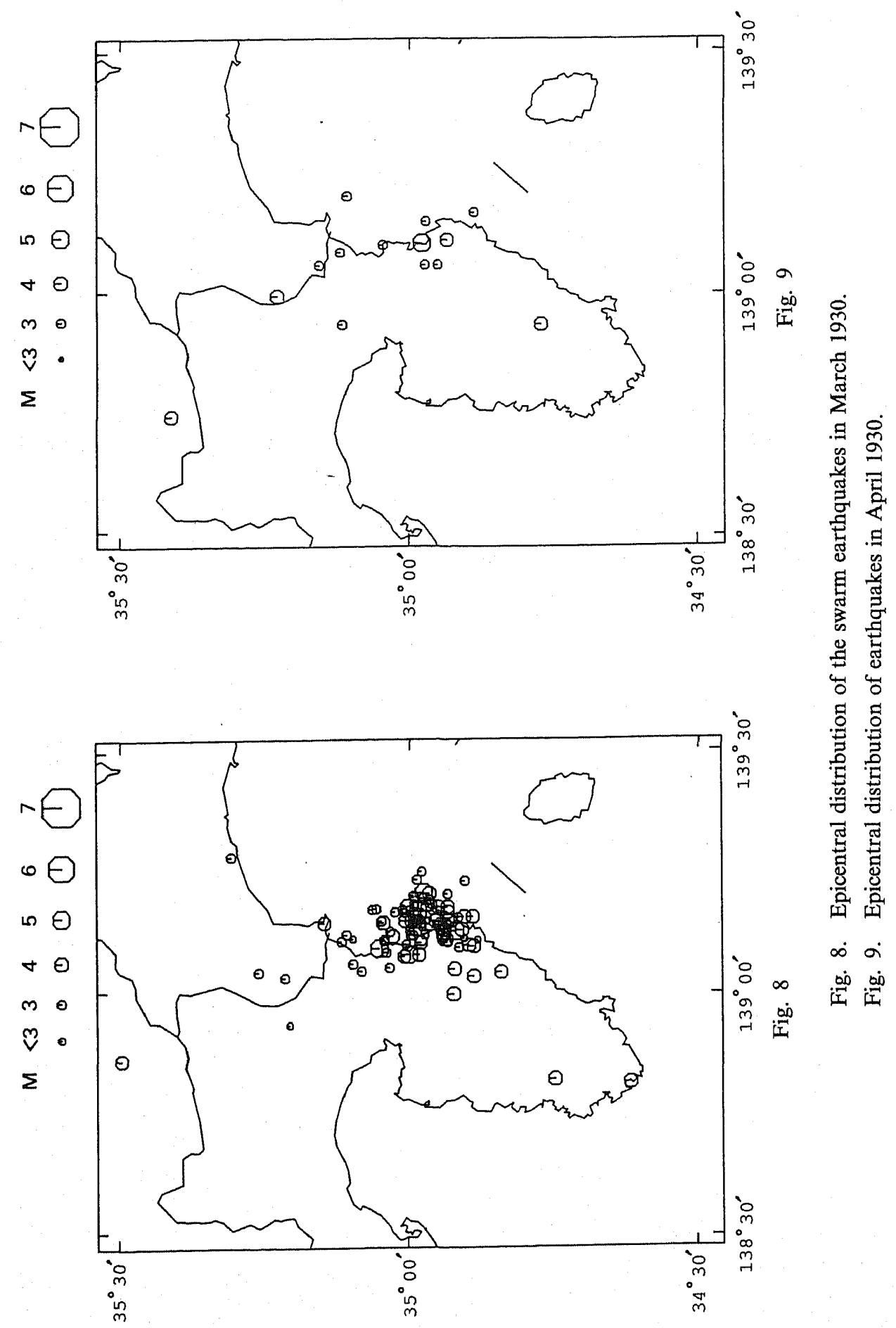

J. Phys. Earth 


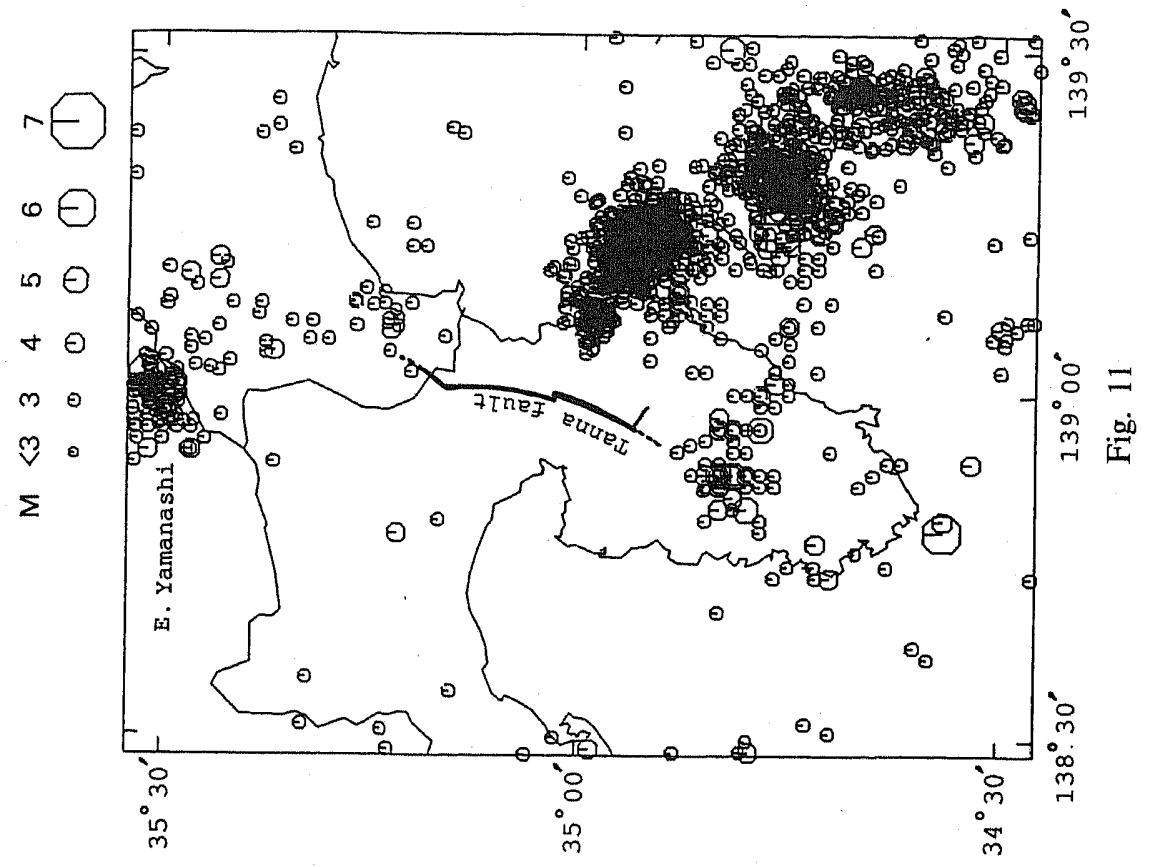

荣 穴 范 要

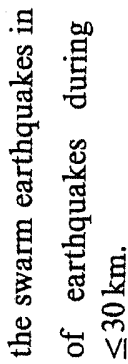

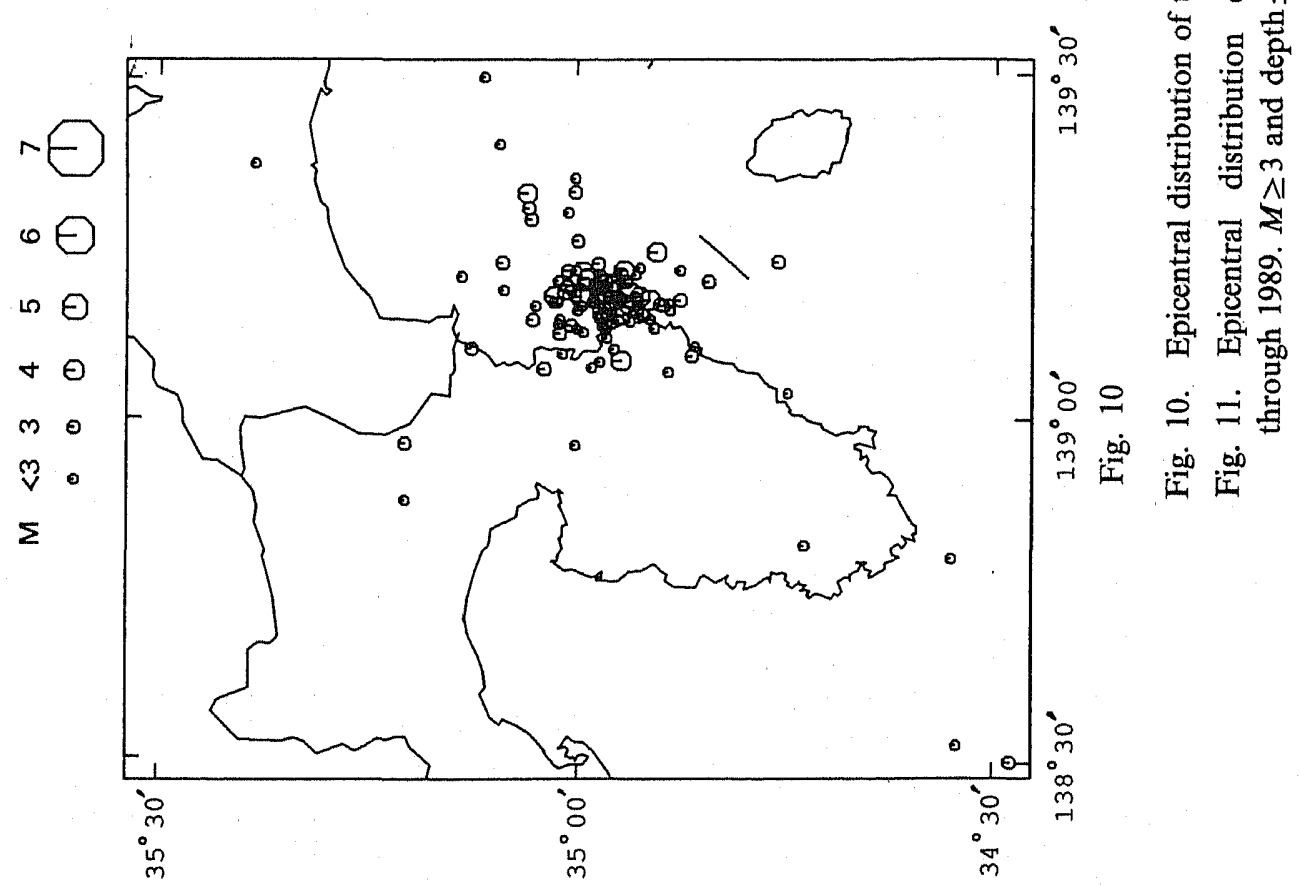

Vol. 39, No. 1, 1991 

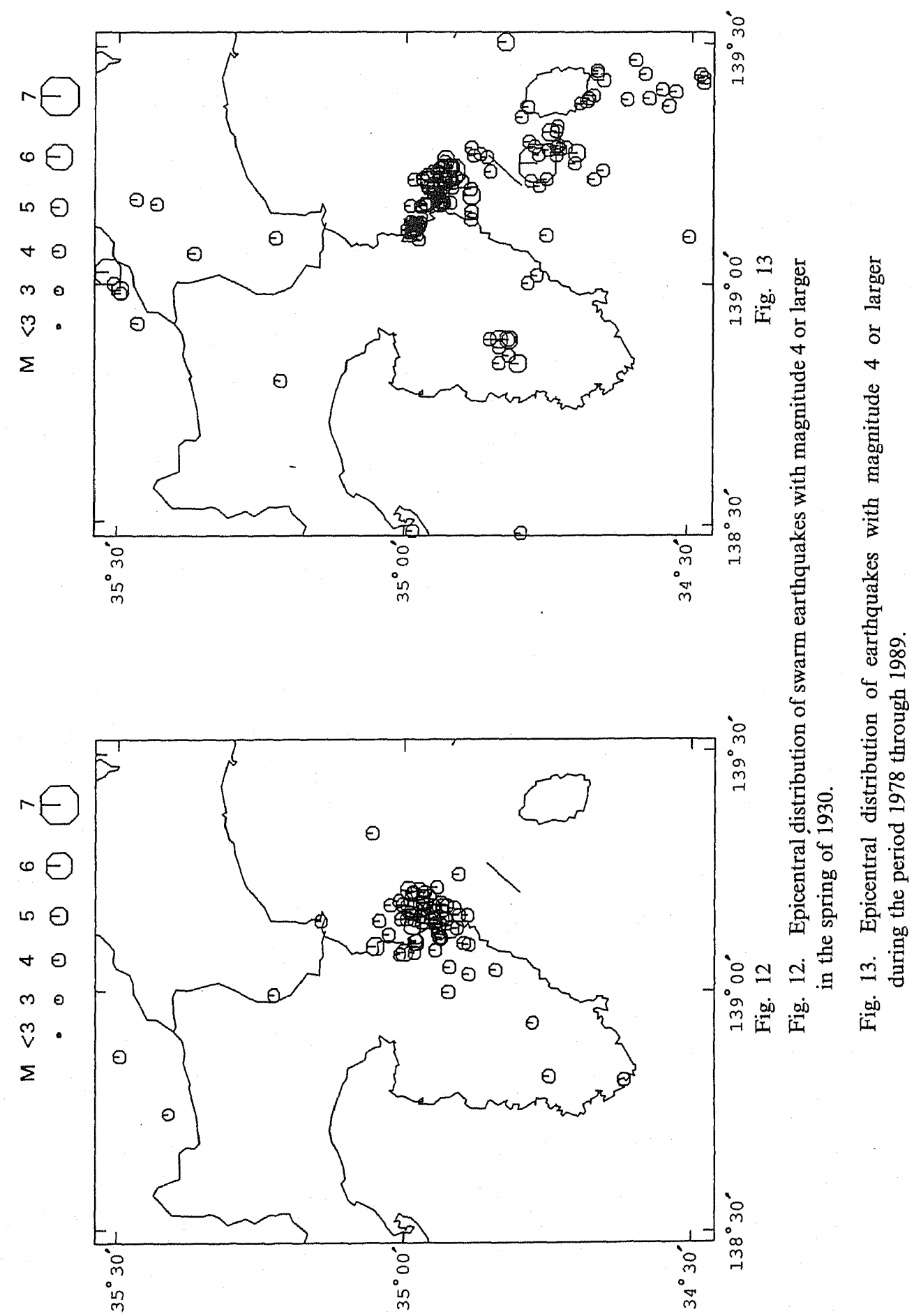
of aftershocks of the Kita-Izu earthquake reflects specific tectonics in the region, i.e. that the Izu Peninsula on the Philippine Sea plate collides with the Eurasian plate. It is interesting to note that the spatial complementarity is observed between the activity associated with the Kita-Izu earthquake and recent activities. That is, recent seismicity has been high in the region to the east of the Tanna fault (see Fig. 11). Implications of this notable feature to the tectonics in and around the Izu Peninsula is discussed in another paper (Yoshida, 1991).

\section{REFERENCES}

Central Weather Observatory, Report on the Kita-Izu earthquake, Central Weather Observatory, 216 pp., 1931 (in Japanese).

Hamada, N., Re-examination of travel time tables for local earthquakes, Pap. Meteorol. Geophys., 35, 109-167, 1984 (in Japanese).

Hamada, N., Re-examination of seismicity associated with destructive earthquakes of Japan and its seismological significance, Pap. Meteorol. Geophys., 38, 77-156, 1987 (in Japanese).

Hamada, N., A. Yoshida, and S. Hashimoto, Improvement of the hypocenter determination program of the Japan Meteorological Agency, Kenshin-jiho, 48, 35-55, 1.984 (in Japanese).

Hayata, K., Epicentral distribution of foreshocks and aftershocks of the severe Kita-Izu earthquake, Kenshin-jiho, 5, 123-130, 1931 (in Japanese).

Ishibashi, K., Possibility of a large earthquake near Odawara, central Japan, preceding the Tokai earthquake, Earthq. Predict. Res., 3, 319-344, 1985.

JMA, Catalogue of relocated major earthquakes in and near Japan (1926-1960), The Seismological Bulletin of the Japan Meteorological Agency, Supplementary Volume, No. 6, 109 pp., 1982.

Kuno, H., Geology and petrology of Omuro-yama volcano group, north Izu, J. Fac. Sci., Univ. Tokyo, Sec. 2, 9, 241-265, 1954.

Matsuda, T., Tanna Fault, The Izu Peninsula, Tokai University Press, Tokyo, 415 pp., 1975 (in Japanese).

Mogi, K., Some features of recent seismic activity in and around Japan (2). Activity before and after great earthquakes, Bull. Earthq. Res. Inst., Univ. Tokyo, 47, 395-417, 1969.

Mogi, K., Seismic activity. Earthquake prediction in and around the Tokyo metropolitan area, Bull. Reg. Comm. Coord. Comm. Earthq. Predict., 2, 20-21, 1980 (in Japanese).

Mogi, K., Active tectonic zone along the Japan sea coast of northeastern Honshu, the Fossa Magna and the Tokai-Izu region, and the recent seismic activity in the Izu region, Bull. Earthq. Res. Inst., Univ. Tokyo, 56, 691-711, 1981 (in Japanese).

Numazu Weather Station, Report on the Kita-Izu earthquake, Numazu Weather Station, 83 pp., 1931 (in Japanese).

OIEP, JMA, Earthquake swarm off the east coast of central Izu Peninsula, June-July, Rep. Coord. Comm. Earthq. Predict. Geogr. Surv. Inst., 25, 134-140, 1981 (in Japanese).

Rikitake, T., Do foreshocks migrate toward the epicenter of main shock?, Proceeding of Autumn Meeting of the Seismological Society of Japan, No. 2, 78, 1980 (in Japanese).

Tsuboi, C., Investigation on the deformation of the earth's crust in Idu Peninsula connected with the Idu earthquake of Nov. 26, 1930, Bull. Earthq. Res. Inst., Univ. Tokyo, 10, 435-448, 1932.

Ueki, S., H. Hamaguchi, Y. Morita, and T. Nishimura, Comparison between the 1930 and 1989 Ito earthquake swarms, Proceeding of Autumn Meeting of the Seismological Society of

Vol. 39, No. 1, 1991 
Japan, No. 2, 122, 1990 (in Japanese).

Yoshida, A., Recent seismic activity and its characteristics in the region in and around the Izu Peninsula, J. Seismol. Soc. Jpn., Ser. 2, 35, 142-144, 1982 (in Japanese).

Yoshida, A., Characteristic patterns in the space-time distribution of large shallow earthquakes in the Japanese Islands, Tectonophysics, 136, 283-297, 1987.

Yoshida, A., Migration of seismic activity along intraplate seismic belts in the Japanese Islands, Tectonophysics, 145, 87-99, 1988.

Yoshida, A., Characteristics of foreshock activities associated with large shallow intraplate earthquakes in the Japanese Islands, Pap. Meteorol. Geophys., 41, 15-32, 1990.

Yoshida, A., On the tectonic cause of the recent activities in the northeastern Izu Peninsula, J. Phys. Earth, 1991 (in press).

Yoshida, A. and S. Mori, Asymmetry of hypocentral distribution of aftershocks between both sides to the fault plane, Proceeding of Autumn Meeting of the Seismological Society of Japan, No. 2, 225, 1987 (in Japanese). 